\title{
Structural features of the vegetative bodies of Hibiscus syriacus $L$. (Sev. Malvaceae Juss.) growing under the conditions in Uzbekistan
}

\author{
Abdikhofiz Rakhimov ${ }^{*}$, Lutfullo Yoziev ${ }^{1}$, and Guljan Duschanova ${ }^{2}$ \\ ${ }^{1}$ Dept. of Natural Sciences, Karshi State University, Karshi, Uzbekistan \\ ${ }^{2}$ Tashkent Botanical Garden named after acad. F.N.Rusanov at the Institute of Botany of the Academy of Sciences of the Republic of \\ Uzbekistan, Tashkent, Uzbekistan
}

\begin{abstract}
The article studies the anatomical structure of the vegetative organs, stems, leaves and leaf blades of Hibiscus syriacus L. in Uzbekistan for the first time.
\end{abstract}

\section{Introduction}

Hibiscus (Syrian hibiscus) is a plant of the Malvaceae family, a species of the genus Hibiscus, native to China, Korea, and West Asia. It is cultivated in open ground in the south of Russia, in the Crimea, in the south of Ukraine, in Moldova and Central Asia. Hibiscus syriacus is a deciduous shrub up to 5-6 $\mathrm{m}$ high. The stalk is thick, treelike, conical in shape, bare, highly leafy, gray, the type of branching is sympodial. Leaves are of medium size (up to $10 \mathrm{~cm}$ long), green, palmate, slightly corrugated. The nerve node is green. Flowers are single or double. They have a very different colour from white to raspberry, sometimes two-tone. Filaments are short, light yellow. Anthers and pollen are light yellow. Stigmas are not protruding. The plant has small boxes, which are ovoid, five-celled with 3 seeds in each nest. Seeds are medium, unrefined. The species is highly fertile, precocious, frostresistant [1].

The anatomical structure of the autonomic organs of Hibiscus syriacus has not been studied in Uzbekistan. This determines the relevance and novelty of our research.

The aim of our research is to study the anatomical structure of the leaf, petiole, and stem of Hibiscus syriacus, in order to determine the diagnostic features of this studied species.

\section{Experimental}

Simultaneously with the morphological description, the vegetative organs (leaf, petiole and stem) were fixed in $700 \mathrm{ml}$ of ethanol for anatomical study. The manual method was used to prepare sections of the vegetative organs. Cross sections of leaf, petiole and stem are prepared manually using a safety razor. Cross sections of the leaf are made through the middle, and the petiole and stem through the base. Sections were stained with methylene blue and safranin, followed by gluing in glycerol-gelatin (Barykina et al., 2004). Descriptions of the main tissues and cells are given according to C. Esau (1969), N. S. Kiseleva (1971), the epidermis - according to S.F. Zakharevich (1954). Microphotographs were taken by a computer microphoton with a Canon A123 digital camera under the Motic B1-220A-3 microscope.

\section{Results and discussion}

The leaf is a vegetative organ of the plant, performing the function of photosynthesis, transpiration and gas exchange. In the Hibiscus syriacus plant, the leaves are green, palmate, slightly corrugated.

On the paradermal section, the outlines of epidermal cells are slightly sinuous, the projection is polygonal. However, the upper epidermis is somewhat different from the lower epidermis. The cells of the upper epidermis are larger than the lower ones.

The leaves are amphistomatic, stomata are located on both sides of the leaf blade, located transversely to the longitudinal axis of the leaf. The shape of the stomata is round-oval.

The upper (adaxial) epidermis has a significantly lower number of stomata compared to the lower (abaxial) epidermis. All this leads to a reduction in water loss from the surface of the sheet. The closing stomata cells on both sides of the leaf are almost the same length. Stomata are submerged, hemiparacitic and anomocytic type (Fig. 1, 2).

Leaf mesophyll is in the cross section of the dorsiventral type, which is represented by palisade cells located under the upper epidermis of the leaf mesophyll, spongy cells - above the lower epidermis of the leaf mesophyll. The epidermis is represented by one row of cells with a thick-walled cuticle layer. Adaxial epidermal cells are larger than abaxial. Between the adaxial and

\footnotetext{
* Corresponding author: abduhofiz@bk.ru
} 
abaxial epidermis there is an assimilation tissue consisting of palisade and spongy cells. The palisade parenchyma is under the adaxial epidermis. The palisade chlorophyllbearing parenchyma is large and elongated, which consists of one row of cells and is located between the adaxial epidermis and the spongy parenchyma of the leaf.

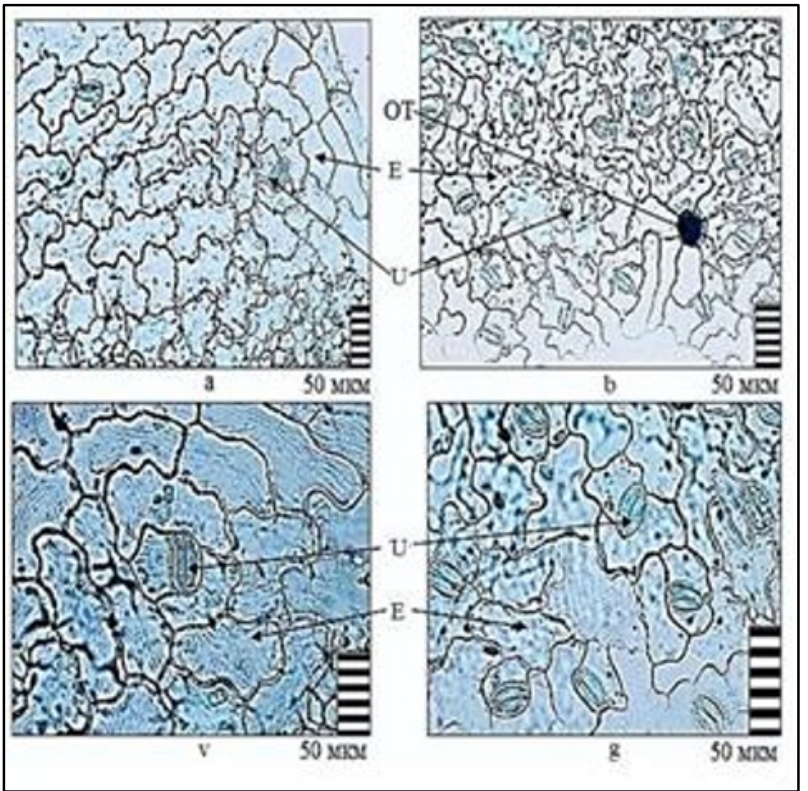

Druse calcium oxalate was found in palisade and spongy cells (Fig. 2).

Fig.1. The structure of the epidermis of the leaf of Hibiscus syriacus on the paradermal section: a-c - adaxial epidermis; Gd - abaxial epidermis. Legend: OT - trichome base, U - stomata, E - epidermis.

The spongy chlorophyll-bearing parenchyma consists of 4-5 rows and is located between the palisade parenchyma and the abaxial epidermis. The spongy parenchyma is round, large and small cell with small cavities. Between palisade and spongy cells there are numerous lateral conducting bundles, with 3-4 small vessels (Fig. 2). The main leaf vein extends on the abaxial side. The rest of the vein is occupied by the main parenchyma, into which 1 conductive bundle is immersed, parenchyma cells are thin-walled, round-oval. Conductive bundles are of closed collateral type, numerous, consisting of phloem and xylem. Xylem is thick-walled, elongated. Their walls are thickened in the form of spirals (Fig. 2). Leaf petiole on an oval cross-section, parenchymal-bundle type, consists of a single-row epidermis. A corner 56 row collenchyme is under the epidermis. Under the collenchyma, 5-6 rows of parenchymal cells are located. In the center of the petiole there is 1 conductive bundle. The conducting bundle is closed collateral, a ring-shaped and sclerified form due to sclerenchyma cells. Parenchymal cells in the central part of the petiole are thin-walled, round, oval, and hydrocyte cells are found (Fig. 3).

The base of the stem on the cross section is rounded, beam type. The structures of the stems of woody plants are due to many years of intensive activity of the apical and lateral meristems. They are powerful, highly lignified, with the early development of secondary integumentary tissue. The integumentary tissue - the cork - consists of several rows of radially located cells with thick corkcovered membranes, and its cells are dark brown, thickwalled, densely closed. Outwardly, during division by tangential septa, the cells of the phellogen are formed by cork cells, and inside - by the cells of the phalloderm (Fig. 4).

The core is not wide, it is represented by large and small round-oval, thin-walled parenchymal cells and they contain hydrocyte cells (Fig. 4).

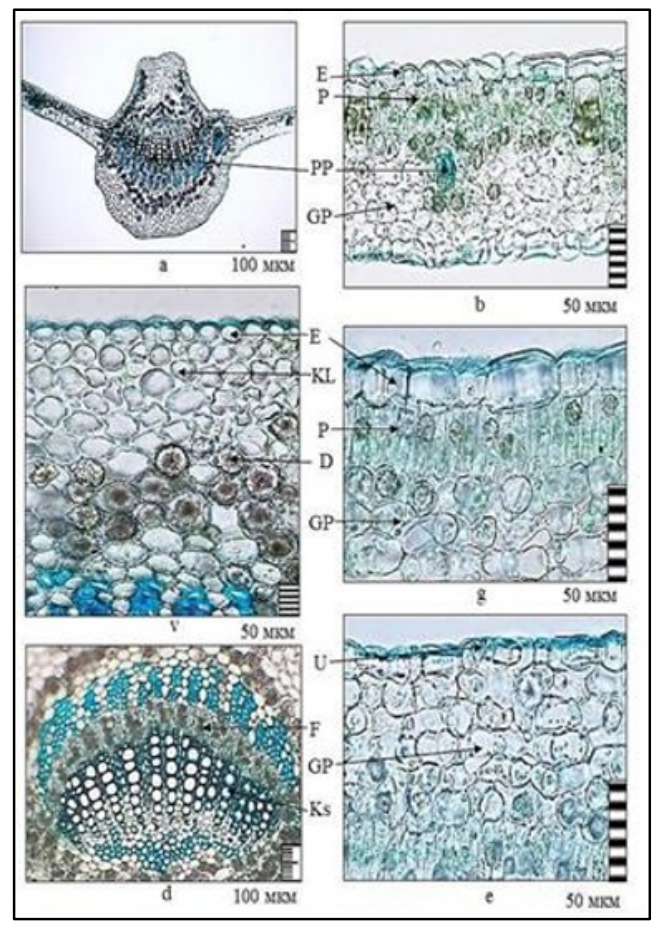

Fig. 2. Anatomical structure of the leaf of Hibiscus syriacus: a - general view of the main vein of the leaf; $b$ - mesophyll leaf; $\mathrm{v}$ - the epidermis and collenchyma, the main vein of the leaf; $g$ - palisade parenchyma; $\mathrm{d}$ - a conductive beam; e - spongy parenchyma and unloaded stomata. Legend: GP - spongy parenchyma, D - drusen, KL - collenchyma, Ks - xylem, P palisade parenchyma, $\mathrm{PP}$ - conducting bundle, U-stomatoma, F

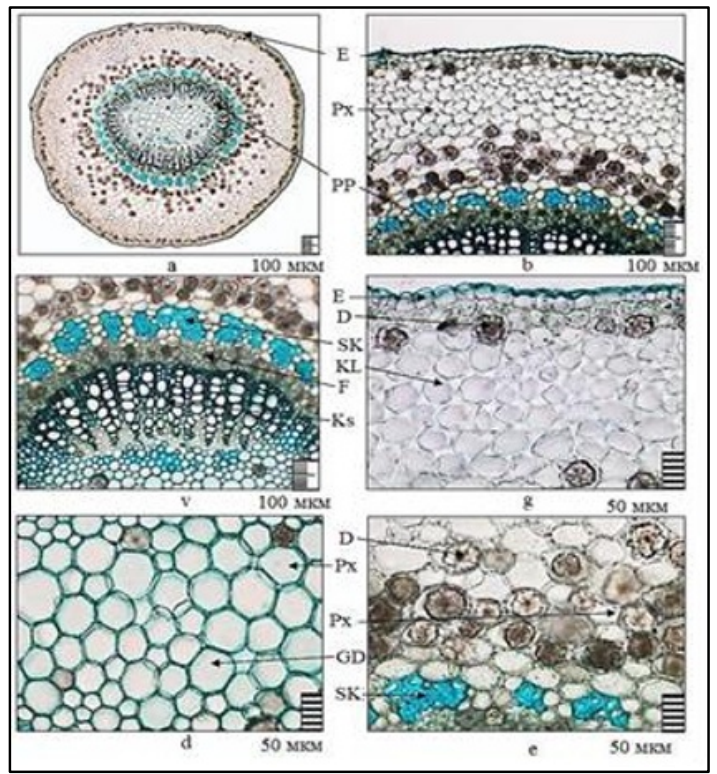

- phloema, E- epidermis.

Fig. 3. The structure of the petiole of the leaf of Hibiscus syriacus L: a-general view; GD - epidermis and collenchyma; 


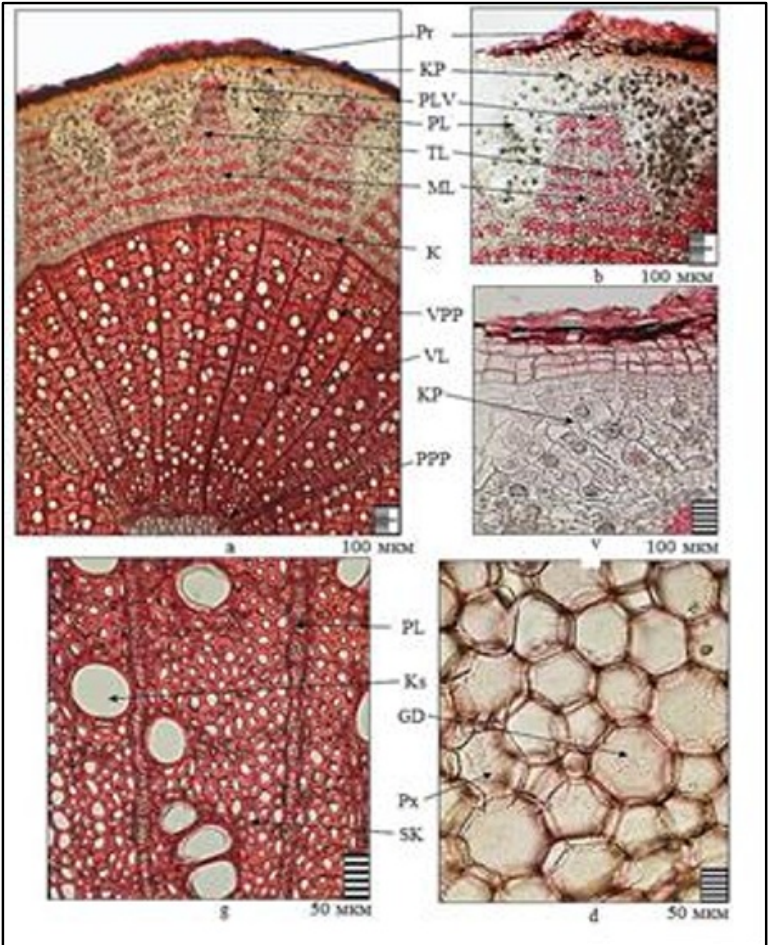

in - a conducting bunch; $\mathrm{d}$ - parenchymal and hydrocytic cells; e - Druse of calcium oxalate. Legend: D - drusen of calcium oxalate, HD - hydrocyte cells, KL - collenchyma, Ks - xylem, Px - parenchyma, PP - conductive beam, SC - sclerenchyma, Fphloem, E-epidermis.

Fig. 4. Anatomical structure of the stem of Hibiscus syriacus in a transverse section: a - general view of the stem; b-in - cow parenchyma; $\mathrm{g}$ - secondary conductive beams; $\mathrm{d}$ - the core. Legend: VL - secondary beam, runway - secondary conductive beams, GD - hydrocyte cells, KP - cortical parenchyma, K cambium, Ks - xylem, ML - soft bast, PL - primary rays, PLV primary bast fibers, SPP - primary conductive bundles, $\mathrm{Pr}$ periderm, Px - parenchyma, RL - radial rays, SC sclerenchyma, TL - hard forehead.

\section{Conclusion}

Thus, the anatomical structure of the vegetative organs of Hibiscus syriacus, growing in the conditions of the Kashkadarya region, was studied. The following diagnostic signs were revealed: in the leaf - slightly sinuous outline of epidermal cells; unburied stomata of anomocytic and hemiparacytic type; dorsiventral type of leaf mesophyll; palisade and spongy chlorophyll-bearing parenchyma; the presence of drusen of calcium oxalate in palisade and parenchymal cells; in the petiole parenchymal-beam type of structure; under the epidermis there is a numerous angular collenchyma; at the edges, the conducting bundle is closed collateral and sclerated; stem type is more lignitied; lignitied elements represent primary bast fibers; the secondary forehead or secondary phloem, which constitutes the secondary cortex, is inward from the fibers; trapezoidal areas consist of lignified thick-walled cells - a hard bast, and thin-walled elements - a soft bast; the libiform is broard, the core is not wide. These identified signs may serve to identify plant materials.

\section{References}

1. R.Kh. Allaberdiev, M.D. Kamalova, Floriculture: History, Theory, Practice: Materials of the VII International Scientific Conference, Minsk. 34 (2016)

2. R.P. Barykina, T.D.Veselova, A.G. Devyatov, Handbook of botanical microtechnology (basics and methods), 6 (2004)

3. K. Esau, Plant anatomy. 416 (1968)

4. N.S. Kiseleva, Anatomy and morphology of plants. 89 (1971)

5. S.F. Zakharevich, Bulletin of Leningrad State University, 4, 65 (1954) 